\title{
Abuso sexual infantil, trauma e depressão na vida adulta: um estudo de caso
}

\section{Child sexual abuse, trauma and depression in adulthood: a case study}

\author{
Omar Moreira Del Bianco (orcid.org/0000-0001-7342-3475) ${ }^{1}$ \\ Rosa Maria Tosta (orcid.org/0000-0003-1166-3398)²
}

\begin{abstract}
Resumo
Este trabalho tem como objetivo verificar e analisar a associação entre os acontecimentos traumáticos na infância — em especial o abuso sexual - e o transtorno depressivo. Fundamenta-se principalmente nos pressupostos psicanalíticos de Winnicott, Ferenczi e Masud Khan. Trata-se de um estudo de caso de uma mulher de sessenta e dois anos que apresentava, no processo psicoterápico, acentuado quadro depressivo e severos sentimentos inconscientes de culpa. As reflexões clínicas derivadas dos questionamentos teórico-práticos trazidos pelo atendimento da paciente e a melhora de sua sintomatologia com a psicoterapia motivaram a elaboração deste artigo. Os resultados indicam que os múltiplos e crônicos traumas intrafamiliares ocorridos na infância foram fatores importantes para o quadro de depressão da paciente, levando a crer que o trauma decorrente do abuso sexual pode ser decisivo para a futura eclosão dessa patologia.
\end{abstract}

Palavras-chave: Depressão. Abuso sexual infantil. Trauma. D.W. Winnicott.

\begin{abstract}
This work aims to verify and analyze the association between traumatic events in childhood — especially sexual abuse - and depressive disorder. It is based mainly on the psychoanalytic assumptions of Winnicott, Ferenczi and Masud Khan. This is a case study of a sixty-two-year-old woman who presented, in the psychotherapeutic process, a marked depression and severe unconscious feelings of guilt. The clinical reflections derived from the theoretical and practical questions brought by the patient's care and the improvement of her symptoms with psychotherapy motivated the elaboration of this article. The results indicate that the multiple and chronic intra-family traumas that occurred in childhood were important factors for the patient's depression, leading to believe that the trauma resulting from sexual abuse may be decisive for the future outbreak of this pathology.
\end{abstract}

Keywords: Depression. Child sexual abuse. Trauma. D.W. Winnicott.

\footnotetext{
1 Pontifícia Universidade Católica de São Paulo, São Paulo, Brasil. E-mail: omardelbianco@gmail.com.

2 Pontifícia Universidade Católica de São Paulo, São Paulo, Brasil. E-mail: rosamariarmt@terra.com.br.
} 
Este trabalho consiste em um estudo teórico-clínico sobre a depressão na perspectiva winnicottiana e sua relação com os traumas intrafamiliares vividos na infância. Fundamenta-se nas elaborações de D.W. Winnicott sobre o estágio do concernimento, base para o estudo da depressão em suas diferentes formas de manifestação, e visa identificar aspectos do cuidado parental na infância associados à doença depressiva. Em razão das contribuições teóricas sobre a natureza e a psicodinâmica do trauma, também recorremos aos trabalhos de Sándor Ferenczi e Masud Khan, autores que se mostraram valiosos para a melhor compreensão do caso clínico estudado. Por fim, revisitamos brevemente as elaborações freudianas sobre o trauma, o que enriqueceu o diálogo com os psicanalistas acima mencionados.

No atendimento a uma senhora, as constantes queixas relacionadas às situações de abuso sofridas na infância, à difícil relação com sua mãe e ao seu permanente humor depressivo fizeram pensar sobre possíveis associações entre esses fenômenos e levaram à necessidade de aprofundar os estudos sobre a depressão, além de buscar literatura sobre o trauma. A partir disso, fundamentados na teoria winnicottiana do amadurecimento pessoal, formulamos a seguinte questão-tema: é possível relacionar as experiências traumáticas infantis - em especial o abuso sexual - com a depressão da paciente em foco?

O abuso sexual infantil apresenta uma elevada incidência epidemiológica, provoca severos comprometimentos ligados ao desenvolvimento das vítimas e é considerado um problema de saúde pública (Habigzang, Koller, Azevedo, \& Machado, 2005; Oliveira et al., 2014). A literatura especializada tem mostrado que as consequências da violência sexual são variadas e numerosas, incluindo efeitos no campo físico e psicológico, tanto a curto quanto a longo prazo (Cantón-Cortés \& Cortés, 2015; Florentino, 2015; Serafim, Saffi, Achá, \& Barros, 2011; WHO, 2003). Dentre as sequelas, a depressão e o sentimento de culpa têm sido extensivamente referidos (Cantón-Cortés \& Cortés, 2015; Florentino, 2015; Habigzang et al., 2005; Sant'Anna \& Baima, 2008; Serafim et al., 2011; WHO, 2003). Para Habigzang, Koller, Azevedo e Machado (2005), a maioria dos abusos sexuais contra crianças ocorre dentro de casa e são perpetrados por pessoas próximas, que desempenham papel de cuidadoras. 
A depressão, por sua vez, representa um grande e crescente problema para a saúde pública. Estima-se que seja a principal causa de incapacidade mental no mundo, e está previsto que se torne a segunda causa de incapacidade para a saúde até 2020 (Blas, Kurup, \& WHO, 2010). No Brasil, a proporção desse transtorno é de $5,8 \%$ da população, país com maior prevalência na América Latina e o segundo das Américas (WHO, 2017). A literatura especializada coloca a depressão como um transtorno de natureza multifatorial (Dalgalarrondo, 2008; Feitosa, 2014; Louzã Neto \& Elkis, 2007), sendo os traumas infantis um dos possíveis fatores associados a essa entidade nosológica (Carr, Martins, Stingel, Lemgruber, \& Juruena, 2013; Figueiredo, 2012; Figueiredo, Dell'aglio, Silva, Souza, \& Argimon, 2013; Martins, 2012; Negele, Kaufhold, Kallenbach, \& Leuzinger-Bohleber, 2015).

Para De Bellis e Zisk (2014), os traumas infantis, particularmente aqueles que são interpessoais, intencionais e crônicos, estão associados a maiores taxas de transtorno ou sintomas de estresse pós-traumático, depressão, ansiedade, comportamentos antissociais e maior risco de transtornos do uso de álcool e substâncias. Além das sequelas mencionadas, a traumatização múltipla ou repetida (cumulative traumata) na infância tem outras graves consequências e afeta vários domínios do desenvolvimento, resultando em sintomas e distúrbios complexos também na idade adulta (Steck \& Steck, 2016). Corroborando os achados mencionados, Negele, Kaufhold, Kallenbach e Leuzinger-Bohleber (2015) concluem que múltiplos traumas na infância podem estar especificamente relacionados a cursos crônicos de depressão. Os traumas infantis frequentemente citados na literatura especializada são: negligência física, negligência emocional, abuso sexual, abuso físico e abuso emocional (Carr et al., 2013; Figueiredo, 2012; Figueiredo et al., 2013; Martins, 2012).

Apesar da crescente produção de estudos dentro da temática da violência sexual, ainda são poucos os avanços consistentes, principalmente na realidade brasileira (Serafim et al., 2011). Paralelamente, embora os trabalhos descritivos da população afetada tenham se multiplicado, ainda há pouca literatura sobre as diretrizes psicoterapêuticas recomendadas e as dificuldades intrínsecas no trabalho de reabilitação das vítimas (Numhauser \& Soto, 2006). Além disso, os estudos demonstram que existe a necessidade de capacitar os profissionais da saúde em geral para o reconhecimento e manejo de situações traumáticas 
(Figueiredo, 2012) e, especificamente, dos sintomas psíquicos relacionados ao abuso sexual (Sant'Anna \& Baima, 2008). Em relação à depressão, ainda existem importantes questões não resolvidas sobre a sua natureza, classificação e etiologia (Beck \& Alford, 2011 ), e novos estudos devem ser realizados para aumentar o conhecimento da relação entre vivências traumáticas precoces e transtornos de humor (Konradt et al., 2013).

Assim, sendo matéria de tamanha relevância no âmbito científico, clínico e da saúde, justifica-se que o conhecimento acadêmico busque abordar as questões relativas à depressão, à violência sexual e a outros traumas na infância. Consideramos que avançar cientificamente na discussão desses temas, ampliando a compreensão das questões relativas aos traumas e à depressão, contribuirá para a elucidação, aos profissionais de saúde, sobre a forma como os fenômenos descritos se relacionam e como a depressão é motivada, gerando conhecimento em saúde e, consequentemente, novas possibilidades de intervenção no trabalho de reabilitação com as vítimas. O deprimir-se pode ser considerado enquanto saúde ou patologia. Conhecer os diferentes tipos de depressão, do ponto de vista winnicottiano, é importante por razão de orientar o psicanalista na escolha do manejo clínico necessário (Moraes, 2014), perspectiva fundamental para a pratica clínica e para o cuidado à saúde.

\section{Método e o caso clínico}

Trata-se de um estudo de natureza qualitativa, que adotou como estratégia de pesquisa o Estudo de Caso, método preferencial em comparação aos outros quando se colocam questões do tipo "como?" ou "por que?", quando o pesquisador tem pouco ou nenhum controle sobre eventos comportamentais e quando o foco de estudo recai sobre fenômenos contemporâneos (Yin, 2015).

Apesar de destacar que a realização de um estudo de caso não é o único meio de investigação psicanalítica, Silva e Macedo (2016) reconhecem o “inegável valor e importância" (p. 524) do estudo de caso clínico para a construção de conhecimento em Psicanálise. Nessa linha, para Yin (2015), o caso único pode representar uma contribuição significativa para a formação do conhecimento e para a construção da teoria. Silva (2013) 
reflexiona que, enquanto estudo de caso, a pesquisa psicanalítica "é construída para ser lida e discutida, a fim de que sua presença no meio acadêmico possibilite a abertura de novas janelas do saber humano interessado em debater os aspectos pesquisados" (p. 43). Além disso, a metodologia da construção de caso possibilita, de acordo com Silva (2013), "que as produções psicanalíticas não se restrinjam aos consultórios, contribuindo com as formações oferecidas nos espaços acadêmicos" (p. 44).

Ao abordar o tema da pesquisa em psicanálise, Naffah Neto e Cintra (2019) comentam que há dois sentidos diferentes que o termo pesquisa assume no trabalho psicanalítico: a pesquisa-escuta e a pesquisa-investigação. A pesquisa-escuta é a "pesquisa clínica por excelência" (Naffah Neto \& Cintra, 2019, p. 24), na qual a atenção flutuante, por parte do analista, e as associações livres, por parte do analisando, contribuem para a produção de sentido. Já a pesquisa-investigação, ou pesquisa teórico metodológica, é a responsável "pelo crescimento e aperfeiçoamento da disciplina psicanalítica, que complementa e dá suporte à pesquisa clínica, recebendo dela, ao mesmo tempo, o estímulo para o seu trabalho construtivo" (Naffah Neto \& Cintra, 2019, p. 24). São duas formas de pesquisa que se complementam, se alternam e se contradizem em uma dialética que nunca se esgota. Seguindo tal entendimento, este trabalho utilizou as perspectivas da pesquisainvestigação (ou teórico metodológica), que tornou possível aprofundar a compreensão sobre os fenômenos em tela; e também utilizou a pesquisa-escuta, visando dar suporte e fundamentação à pesquisa-investigativa, iluminando o caso analisado.

De acordo com Tosta (2019), em um caso clínico geralmente se constrói uma narrativa da história pessoal e familiar, tomada a partir da relação pesquisador-pesquisado. Para a construção dessa narrativa, o recorte do presente estudo abrangeu os dois primeiros anos do tratamento psicológico de uma senhora, aqui denominada Rebeca (nome fictício), o qual ocorreu com frequência quinzenal, totalizando 41 sessões de 50 minutos cada. $O$ conteúdo das sessões foi registrado ao término do atendimento, constituindo um diário das sessões de psicoterapia. Esse material foi posteriormente analisado tomando como base o referencial teórico psicanalítico que embasou este estudo. Durante esse período de dois anos, o caso foi tratado e analisado apenas em supervisão clínica. 
Em 2015, Rebeca, de sessenta e dois anos, procurou atendimento psicológico relatando possuir intensos sintomas depressivos e o diagnóstico médico de "Depressão Profunda" (sic). Rebeca também tinha "compulsão pelo banho" (sic), segundo ela causada pelo fato de se sentir "suja" (sic). Os sentimentos de inutilidade e desesperança eram recorrentes em sua vida, assim como os pensamentos suicidas e autodestrutivos. Tinha constantes pesadelos de cunho sexual e de ser perseguida por diferentes homens.

No início do processo de psicoterapia, ainda nos primeiros seis meses, a sensação de sentir-se "suja" era frequentemente associada às experiências de abuso sofridas durante a infância, quando tinha por volta de oito ou nove anos, sendo o perpetrador o seu próprio pai - dizia: "(o se sentir suja) tem a ver com quando o meu pai me procurava para apalpar o meu corpo" (sic). As sessões iniciais do tratamento foram substancialmente dedicadas para o tema do abuso sexual e suas implicações em sua vida adulta. Rebeca se sentia profundamente responsável por ter feito coisas que puderam, de alguma forma, ter motivado o comportamento de abuso por parte de seu pai, e se condenava por não ter feito nada para evitá-lo.

Passada a etapa inicial do processo de psicoterapia, outras questões se revelaram igualmente significativas: revelou, com culpa e repugnância, ter presenciado o intercurso sexual dos seus pais quando tinha apenas cinco anos; além disso, verbalizava que durante toda sua infância era constantemente criticada, ameaçada e castigada pela sua mãe, uma mulher que era tida como pouco afetuosa, rígida e ausente quanto aos cuidados emocionais e físicos de sua filha. Tratava-se de uma mãe que nunca esteve devidamente disponível para receber os possíveis gestos de carinho de Rebeca, e a quem nunca era possível satisfazer. No atendimento, Rebeca questionava (quanto ao tema do abuso sexual): "será que ela (mãe) não sabia o que estava acontecendo comigo? Não é possível [...]" (sic). Para agravar o quadro, relembra outro acontecimento relevante de sua infância: sobre ter sofrido prejuízos adicionais quando precisou dividir o cuidado materno após o nascimento de sua irmã, que "era loirinha, clarinha e dos cabelos cacheados" (sic).

Ao longo do processo terapêutico, as associações referentes ao "sentir-se suja" foram se desvinculando das situações de abuso sexual e se vinculando à difícil relação com a mãe. A paciente passou a considerar a possibilidade de que os seus sintomas obsessivo- 
compulsivos tivessem mais a ver com a falta de um cuidado íntimo e pessoal por parte de sua mãe e a decorrente raiva que sentia de sua progenitora, sentimento que muitas vezes parecia superar o amor. E algo mais saltava aos olhos do terapeuta, despertando o seu interesse por um aprofundamento clínico e teórico sobre o tema: apesar das inúmeras agressões sofridas por parte dos pais, Rebeca não demonstrava qualquer tipo de sentimento mais hostil dirigido a eles. Parecia não sentir raiva alguma. Após o primeiro ano de análise, quando passou a reconhecer o ódio que sentia em relação aos pais, disse: "é como se eu não amei, então talvez eu não deva ser amada [...]" (sic). Em outra oportunidade, comentou: "[...] eu não me permito sentir raiva da minha mãe. Às vezes minha irmã quer falar mal dela, falar coisas sobre ela, mas não permito, sinto que estou traindo ela" (sic). Afirmações como essas revelavam problemas em relação à capacidade para a ambivalência, a qual não foi anteriormente alcançada ou foi perdida, característica que - à luz da teoria winnicottiana das depressões - configurava uma depressão do tipo melancólica. A debilidade na capacidade para direcionar amor e ódio para uma mesma pessoa foi tema frequentemente emergente na relação terapeuta-paciente, sendo a conquista dessa capacidade um importante objetivo traçado para a psicoterapia de Rebeca.

\section{Aportes teóricos}

Em Winnicott, a chave para a compreensão das depressões e do sentimento de culpa é encontrada na fase do amadurecimento denominada de estágio do concernimento ou posição depressiva (Moraes, 2014; Winnicott, 1958/1983, 1990, 1954/1993), um estágio normal do desenvolvimento emocional. É uma conquista que permite que o bebê seja capaz de ter sentimento de culpa, possibilitando-o se envolver nos relacionamentos e se preocupar com os outros em razão de seus componentes instintivos ou excitados (Winnicott, 1990).

A "capacidade para deprimir-se" é uma aquisição do crescimento individual que pode conduzir à maturidade pessoal e "é evidência de crescimento e saúde no desenvolvimento emocional do indivíduo" (Winnicott, 1958/2011a, p. 87). É uma capacidade que está relacionada à força do ego, ao estabelecimento do self e à descoberta de uma identidade 
pessoal (Winnicott, 1963/2011b), perspectivas relacionadas à saúde. É anterior ao complexo de Édipo, e seu desenvolvimento se liga especialmente ao período da relação dual (Winnicott, 1963/2012). O estágio do concernimento está inserido no período da dependência relativa, iniciando-se depois que a criança adquire o "status de unidade", quando está apta para distinguir o mundo interno do mundo externo. No estágio de dependência absoluta, o bebê ainda não apresenta qualquer preocupação quanto aos resultados do amor pulsional, sendo apenas posteriormente, no estágio do concernimento, que os instintos finalmente podem passar a ser considerados intenções pessoais (Winnicott, 1954/1993).

Durante esse estágio, o bebê necessita de tempo e de um "ambiente pessoal contínuo" (Winnicott, 1990, p. 89) para que possa elaborar as consequências das experiências pulsionais e integrar, no seu interior, a existência da mãe-ambiente e da mãeobjeto, e "é exatamente aqui que enormes dificuldades podem surgir" (Winnicott, 1954/1993, p. 443). É insustentável para o bebê a aceitação de que a mãe das fases tranquilas (mãe-ambiente) é a mesma mãe que é duramente atacada nas fases excitadas (mãe-objeto), sendo ele incapaz de suportar o peso da culpa e do medo resultantes desse reconhecimento (Winnicott, 1990). Porém, a aceitação e a integração entre esses dois aspectos da mãe podem ser feitas através de um ambiente suficientemente bom, o qual é representado pela mãe que sobrevive e sustenta a situação no tempo. É a presença contínua da mãe que possibilitará que o amor e ódio coexistentes no bebê sejam separados, interrelacionados e gradualmente controlados de dentro, de uma forma saudável (Winnicott, 1954/1993).

De acordo com Winnicott (1954/1993), para que a conquista do concernimento seja alcançada, é preciso que seja confirmada ao longo do tempo até que se estabeleça o círculo benigno e o reforço diário dessa operação. Com o transcorrer do círculo benigno, a criança passa a tolerar a preocupação e a culpa decorrentes dos vários efeitos destrutivos e "machucados" feitos ao corpo da mãe, pois começa a reconhecer, com o tempo, que algo pode ser feito à mãe. Algo que acredita ter machucado, subtraído ou destruído, pode ser reparado, reconstruído. São as experiências de reparação e de restituição que possibilitam o ser humano suportar a destrutividade que está na base do amor instintivo. Na saúde, o 
indivíduo torna-se "capaz de um reconhecimento quase pleno dos fatores agressivos e destrutivos presentes no amor instintivo e das fantasias inerentes a eles" (Winnicott, 1990, p. 92).

Também no estágio do concernimento ocorre a diferenciação gradual entre fatos e fantasias, ou melhor, a base do "reconhecimento de idéias, fantasias, elaboração imaginativa da função, a aceitação das idéias e da fantasia relacionada ao fato, mas que não deve ser confundido com ele" (Winnicott, 1954/1993, p. 444). Especialmente sobre fatos e fantasias, Winnicott (1990) discorre que nos sonhos das garotas não podem ser evitadas, entre outras: (a) a ideia da morte da mãe; (b) a ideia de estar roubando da mãe o seu marido, seu pênis e; (c) a ideia de ver-se à mercê da sexualidade do pai. Diz, com efeito, que em situações familiares adequadas, a solução para essas ideias, e para as angustias delas decorrentes, vêm da possibilidade de distinguir entre o que é chamado de realidade e fantasia, sendo a cena primária (os pais sexualmente juntos) a base de estabilidade do indivíduo.

De acordo com Winnicott (1963/2011b), o humor depressivo e sua resolução é uma questão da reorganização interna dos elementos bons e maus, isto é, da reavaliação interna das novas experiências e ideias destrutivas que acompanham o amor. A depressão representa o tempo e a condição necessária para que o mundo interno seja resignificado e seus elementos reorganizados (Winnicott, 1963/2011b), sendo por isso que Winnicott (1954/1993) compreende esse estado clínico como um mecanismo curativo.

Sinteticamente, nos achados winnicottianos, a depressão pode ser compreendida enquanto (a) sinal de amadurecimento e de um desenvolvimento normal, relacionada a uma capacidade e indicativa de saúde, e (b) como uma patologia relacionada à interrupção do desenvolvimento emocional (Abram, 2000; Amaral, 2006; Vidal \& Lowenkron, 2008). Para Moraes (2014) dois são os principais tipos de depressão em Winnicott, a saber: (1) a reativa, que pode ser simples e patológica e; (2) a psicótica. Em relação às psicóticas, estamos naquilo que Winnicott denomina de "impurezas do humor deprimido". Sete situações estariam sob o domínio das depressões com impurezas: (1) os fracassos de organização do ego; (2) depressão com delírios persecutórios; (3) hipocondria e doenças somáticas; (4) defesa maníaca/hipomania; (5) oscilação maníaco-depressiva; (6) exageros das fronteiras do ego e; (7) melancolia e mau humor (Winnicott, 1963/201 1b). 
A depressão é marcada por impurezas quando não há integração da experiência agressiva na etapa de dependência relativa, ou melhor, a dificuldade de o sujeito em se preocupar com o outro (visível nas depressões impuras) teria, em sua gênese, defesas ligadas ao controle do ódio, associado à agressividade não integrada (Vidal \& Lowenkron, 2008). Paralelamente, consoante Moraes (2014), as falhas nas depressões psicóticas estariam relacionadas à estruturação da personalidade ou ao desfazimento da integração pela quebra do círculo benigno. Assim, é a força do ego e a maturidade pessoal do indivíduo que se relacionam intimamente ao estudo das diferentes formas de manifestação e à "pureza do humor depressivo" (Moraes, 2014; Winnicott, 1963/2011b, p. 67). O estudo e o diagnóstico da depressão devem ser feitos com base nessa perspectiva.

Particularmente sobre a melancolia, o que se observa no paciente é um insuportável estado clínico marcado pelo humor "anti-social e destrutivo, ainda que o ódio do paciente não esteja presente" (Winnicott, 1963/2011b, p. 67). Conforme Winnicott (1958/1983), a melancolia é uma forma organizada de depressão onde o paciente é paralisado por um sentimento de culpa e se acusa de ter causado as inúmeras mazelas sociais. Ao reivindicar para si a culpa de todas as pessoas e malfeitos do mundo, o melancólico estaria, em última análise, evitando entrar em contato com a sua própria destrutividade.

Por fim, em relação à noção de trauma, Winnicott (1965/1994) o conceitualiza como "um fracasso em relação à dependência" (p. 113), o que envolve uma consideração de fatores externos. Para o autor, a ideia de trauma tem diferentes significados em função do estágio do desenvolvimento emocional da criança, que vai da dependência à independência. Para Fulgencio (2004), sob a ótica winnicottiana, todos os tipos de trauma podem ser concebidos em termos relacionais, visto que não são as intensidades energéticas que definem o trauma, e sim o que determinado tipo de relação com o outro significa quanto à continuidade de ser e à confiabilidade no ambiente.

Consoante Ferenczi (1933/1992), o trauma pode ser causado pela confusão de línguas entre os adultos e a criança. Na situação de abuso sexual, o agressor confunde a sua linguagem, a da paixão, comum aos adultos por já terem atingido a maturidade sexual, com a linguagem de ternura da criança, que é a língua do lúdico, das fantasias lúdicas, e não do amor sensual, mesmo que o jogo venha a assumir uma forma erótica. O trauma psíquico 
infantil não se reduz à ocorrência de um abuso sexual exercido por um adulto sobre uma criança, apesar da insistência do autor sobre a importância do traumatismo sexual como fator patogênico. As medidas punitivas insuportáveis e passionais, bem como o "terrorismo do sofrimento" também são fatores traumáticos relevantes (Ferenczi, 1933/1992). Para Perón (2007), na perspectiva ferencziana o trauma pode ser considerado como um quantum de excitação intensa demais para o escoamento psíquico normal, o que provoca marcas psíquicas singulares no indivíduo. O traumático é da ordem do excesso, não sendo a criança capaz de absorver, por conta de seu aparelho psíquico ainda em formação, o impacto de um evento - ou vários - incompreensível e excessivoi.

\section{Análise do caso clínico}

Quando realizamos uma aproximação entre a teoria winnicottiana da depressão e o caso clínico, algumas hipóteses puderam ser levantadas. Inicialmente, consideramos a possibilidade de que, embora a cena primária vivida na fantasia possa ser a base de estabilidade do indivíduo, a visão real do intercurso sexual de seus pais pode ter sido um importante fator traumático associado à depressão de Rebeca. Isso porque, de acordo com Winnicott (1990) presenciar a cena primária pode provocar na criança "uma tensão máxima [...]" (p. 77) tornando-se "traumática, de forma a fazer com que a criança forçada a testemunhá-la passe a desenvolver uma doença" (p. 77). Aqui o traumático parece estar relacionado à impossibilidade de se alcançar um discernimento efetivo entre fatos e fantasias. Entendemos que uma inconsistência desse tipo no estágio do concernimento pode ter levado Rebeca a arrastar alguma confusão quanto a realidade factual do conteúdo destrutivo de seu mundo interno, o que pode ter gerado dificuldades para que a conquista do concernimento se tornasse um fenômeno estabelecido. Desse modo, a paciente pode ter carregado "impurezas" que complicaram a sua tarefa de gerir seu mundo interno.

Reflexões semelhantes realizadas pelo psicanalista foram feitas a respeito do abuso sexual infantil sofrido por Rebeca, e cinco pontos principais foram levantados em seu processo psicoterápico: (1) a fantasia de estar roubando da mãe o seu marido e a ideia de ver-se à mercê da sexualidade do pai se tornaram realidade, ocasionando novamente uma 
confusão entre fatos e fantasias, prejudicando, por fim, a conquista da capacidade para a ambivalência; (2) por carregar dúvidas quanto à diferenciação entre os fenômenos internos e externos, o ódio pela mãe precisou ser afastado e duramente reprimido (prejudicando mais uma vez a conquista da capacidade para a ambivalência), pois, do contrário, sua mãe sairia morta; (3) o fato de, mesmo contra a sua vontade, ter se relacionado sexualmente com o pai, isto é, de ter roubado - no seu imaginário - o marido de sua mãe. Esse fato, no plano inconsciente, configurou-se como uma severa violência feita à mãe, destituindo-a de sua função de esposa (danos imaginativamente causados à mãe), gerando um profundo sentimento inconsciente de culpa; (4) o medo, a falta de amor e o ódio do agressor, o seu próprio pai, e a consequente dificuldade para lidar com toda a carga destrutiva e agressiva em relação a ele. A intrusão súbita ou imprevisível de fatos reais (abuso) gerou ódio em Rebeca, "ódio do objeto bom experenciado não como ódio, mas delirantemente, como sendo odiad(a)" (Winnicott, 1965/1994, p. 115), algo possível de ser analisado em seus frequentes sonhos nos quais é perseguida por homens que queriam lhe fazer algum mal e; (5) o profundo ódio sentido em relação à mãe tanto por não ter interditado o incesto, como também - e especialmente - por ter sido conivente com ele. Quanto aos dois últimos itens cabe ressaltar que, sobre sua natureza, "o trauma é aquilo que rompe a idealização de um objeto pelo ódio do indivíduo, reativo ao fracasso desse objeto em desempenhar a sua função" (Winnicott, 1965/1994, p. 113).

De acordo com Ferenczi (1933/1992), a criança, frente à situação de abuso sexual, reage ao brusco desprazer "pela identificação ansiosa e a introjeção daquele que a ameaça e a agride" (p. 103), e não pela defesa. Talvez essa observação ajude a entender o motivo pelo qual Rebeca se recusava a reagir ao agravo sofrido com ódio ou com defesa. Ao invés disso, a mudança significativa provocada na criança por essa identificação com o adulto (seu pai), foi "a introjeção do sentimento de culpa do adulto" (Ferenczi, 1933/1992, p. 102). E continua Ferenczi (1933/1992) afirmando que a criança, se conseguir se recuperar de tal agressão, se sentirá intensamente confusa e dividida entre a sua inocência e culpa. De acordo com o autor,

[...] o sentimento de culpabilidade, no erotismo adulto, transforma o objeto de amor em objeto de ódio e de afeição, ou seja, um objeto ambivalente. Ainda que essa 
dualidade inexista na criança no estágio da ternura, é justamente esse ódio que surpreende, assusta e traumatiza uma criança amada por um adulto. Esse ódio transforma um ser que brinca espontaneamente, e com toda a inocência, num autômato, culpado do amor [...]. É o sentimento de culpa e ódio contra o sedutor que conferem às relações amorosas dos adultos o aspecto de uma luta assustadora para a criança [...]. (Ferenczi, 1933/1992, p. 106)

Essas contribuições ferenczianas sobre abuso sexual infantil são úteis para a melhor compreensão das marcas traumáticas observadas na dinâmica psíquica de Rebeca, pois relacionam o conceito de trauma relativo à confusão de língua da ternura e da paixão ao sentimento de culpa e ao ódio. Assim, podemos refletir, com base na citação acima, que é a dificuldade para lidar com o ódio decorrente da situação de abuso que pode ter sido especialmente traumática para Rebeca. Com base nos aportes winnicottianos, essa dificuldade parece ser da ordem da capacidade para a ambivalência, isto é, do conflito relativo à coexistência entre amor e ódio dirigidos ao pai. Destacamos que, para Winnicott (1965/1994), “onde a reação é de raiva ou ódio apropriados, a expressão 'trauma' não é bem aplicada" (p. 114). Em relação às reflexões expostas até esse ponto devemos lembrar que, para Winnicott (1963/2011b), a base da psicologia da depressão está relacionada à elaboração do ódio, ou seja, à dificuldade em aceitar o ódio inerente ao amor.

Cabe aqui um importante parêntese a respeito da "inocência infantil" mencionada por Ferencziii. Embora sejam óbvias as diferenças das vivências da sexualidade de uma criança e de um adulto, torna-se válido - ao abordarmos o tema da sexualidade infantil - trazer para a discussão o texto "Três ensaios sobre a teoria da sexualidade", de Freud (1905/1972). Nesses artigos, o autor anuncia justamente a perda da "inocência infantil", afirmando se tratar "um erro que tem tido graves consequências" (p. 177) a ideia popular de que o instinto sexual está ausente na infância. Na oportunidade, o que Freud (1905/1972) faz é colocar a criança como um ser desejante, que busca obter a satisfação adequada do instinto, de modo que "a vida sexual infantil [...] exibe componentes que desde o início envolvem pessoas como objetos sexuais" (p. 197), o que inclui, evidentemente, os próprios pais. Tendo a criança a sua sexualidade, com seus desejos, prazeres e objetos, fica mais fácil compreendermos o sentimento (inconsciente) de culpa decorrente do abuso sexual 
sofrido por Rebeca. Para Goldgrub (1988), "o trauma sexual talvez não possa ser vivenciado sem um certo prazer por parte da vítima" (pp. 45-46), rememoração que se torna traumatizante na adolescência em função da obscura consciência de alguma cumplicidade. E prossegue o autor, afirmando que

Essa auto-acusação, entretanto, significaria, na verdade, a transposição de um sentido atual para o passado; na adolescência, a atração exercida pela sexualidade destila um prazer com frequência associado à culpa [...]. Maior ou menor, o reconhecimento do próprio desejo sexual, julgado inaceitável, faz emergir a recordação da vivência sexual infantil e lhe acrescenta, de maneira falsa, mas lógica, o agravante da participação voluntária. O sintoma então é a expressão disfarçada do acontecimento cuja lembrança foi expulsa da consciência, o preço pago para poder acreditar na própria inocência. (Goldgrub, 1988, p. 46)

Além do trauma sexual provocado pelo pai, vimos que Rebeca também sofreu negligência física e negligência emocional por parte de sua mãe, uma mulher desatenta e afetivamente distante, quadro que se potencializou após o nascimento de sua irmã. No atendimento, Rebeca relatava que sempre recebera pouquíssimo carinho e cuidado de sua mãe e que "vivia suja, largada" (sic). Sobre essas negligências, Winnicott (1990) chama a atenção para os riscos que um cuidado instável pode gerar na criança, quando, por exemplo, a pessoa que alimenta de manhã não é a mesma que alimenta à tarde ou noite, ou quando o cuidado é impessoal e mecânico. Essa ausência de uma continuidade do relacionamento pessoal entre Rebeca e sua mãe pode ter provocado prejuízos no desenvolvimento da capacidade de fazer reparações, a qual pode ter sido, inclusive, desperdiçada. Para Winnicott (1963/1983), o fracasso da reparação impossibilita o desenvolvimento da capacidade de se preocupar (e, com efeito, da capacidade para a ambivalência), cedendo lugar às formas mais primitivas de culpa e ansiedade.

Como se não bastasse, Rebeca teve uma mãe extremamente crítica, sendo inúmeras vezes ameaçada e duramente admoestada por ela, ou seja, houve abusos emocionais que configuram um outro tipo de trauma infantil. Não podemos ignorar, ainda, as diversas situações de abuso físico geradas pela mãe. Reflexionamos que as consequências de tais traumas sofridos por Rebeca podem ser compreendidas tomando como base Ferenczi 
(1933/1992), que descreve outro importante fator traumático fora do contexto da sexualidade: as medidas punitivas insuportáveis. Nesse tipo de trauma, discorre o autor, as transgressões praticadas pela criança, de brincadeira, "passam a ter um caráter de realidade pelas punições passionais que recebem de adultos furiosos [...] o que acarreta numa criança, não culpada até então, todas as consequências da depressão" (Ferenczi, 1933/1992, p. 104, grifos nossos). Com base no exposto, e relacionando com a teoria winnicottiana da depressão, podemos conjecturar que a as punições passionais também podem ter gerado dificuldades na diferenciação entre fatos ("caráter de realidade") e fantasias, além de culpa insuportável em Rebeca. Esses fenômenos contribuíram para que a conquista do concernimento não pudesse ter sido alcançada pela paciente. A consequência final foi a grave depressão (melancólica) apresentada por Rebeca, patologia relacionada à interrupção de seu desenvolvimento emocional.

Esse caráter repetitivo e duradouro das falhas ambientais maternas ocorridas na infância leva ao que Khan (1963/1984) denominou de Trauma Cumulativo, conceito que recebeu uma forte influência winnicottiana, e que pode contribuir para a compreensão do processo de adoecimento de Rebeca. De acordo com Khan (1963/1984), "o trauma cumulativo resulta das fendas observadas no papel da mãe como escudo protetor" (p. 62), durante todo o período em que as funções do ego da criança ainda são imaturas e instáveis. Ao contrário da mãe de Rebeca, que era muito "desatenta e despreocupada" (sic) com a sua filha, o papel da mãe como escudo protetor "é uma atitude de alerta, de adaptação e organização" (Khan, 1963/1984, p. 67).

Para Khan (1963/1984), no contexto do trauma cumulativo, o interjogo entre mãe e filho pode apresentar, entre outros, o seguinte efeito na criança: "pode dar início à organização de uma conformidade especial ao temperamento da mãe, conformidade essa que cria um desequilíbrio na integração dos impulsos agressivos" (p. 70). Deduzimos, desse modo, que o trauma cumulativo pode gerar dificuldades no campo da capacidade para a ambivalência, o que está relacionado com casos mais graves de depressão na perspectiva winnicottiana. À luz da teoria do amadurecimento pessoal, a inibição do instinto e da capacidade para amar, atacar ou odiar, bem como a depressão patológica, são algumas das consequências prováveis de uma mãe distante, que muda de atitude e que é incapaz de 
receber (com alegria) "o gesto não só para reparar, mas também para simplesmente dar que surge de seu bebê" (Anfusso \& Indart, 2009, p. 118, tradução nossa). É possível que a intromissão das necessidades e conflitos pessoais da mãe, que caracteriza o seu fracasso no tocante ao papel que desempenha como escudo protetor, possa ter impossibilitado que Rebeca tivesse recebido os cuidados maternos fundamentais relativos ao estágio do concernimento. Assim, quando a capacidade de fazer reparações é desperdiçada, o círculo benigno não pode ser estabelecido, fazendo com que a capacidade para a ambivalência não seja alcançada e o indivíduo carregue impurezas em sua depressão (Moraes, 2014; Winnicott, 1990). Como consequência de um círculo benigno que não pode ser estabelecido, Rebeca manifestava uma sensação de culpa permanente, constante sentimento de inadequação quando avaliava as consequências de seus atos, além de retraimento e inibição dos instintos. Para Amaral (2006), o humor depressivo prevalece toda vez que o ciclo benigno se quebra.

Nos casos em que os excessos do sentimento de culpa estão presentes, encontramos doenças como a melancolia e a neurose obsessiva, enfermidades que se inter-relacionam e que podem se alternar em um mesmo paciente (Winnicott, 1958/1983). Esse parece ser o caso de Rebeca. Tomando como base os aportes teóricos winnicottianos, poderíamos conjecturar que, em relação à sua neurose obsessiva, o estado de confusão - caracterizado pelos rituais (banhar-se excessivamente) e pelo pensamento obsessivo (ser/estar suja) era mantido com a função de ocultar "o fato de, em alguma situação específica da qual o paciente não é consciente, o ódio foi mais poderoso do que o amor" (Winnicott, 1958/1983, p. 23).

Com a ajuda da psicoterapia, Rebeca pode reconhecer e expressar sua raiva e suas ideias agressivas inicialmente relacionadas ao pai, o que já se mostrou salutar para a atenuação de seus sintomas depressivos. Porém, uma melhora significativa da sintomatologia obsessiva e depressiva ocorreu a partir do momento da psicoterapia em que Rebeca passou a entrar em contato com os seus sentimentos ambivalentes e a se sentir mais livre e segura para odiar, além de seu pai, a sua mãe. Nas suas próprias palavras: "[...] Eu via outras mães cuidando bem das suas filhas, e isso eu não tinha. Eu sentia raiva dela, é isso, raiva e frustração, decepção [...]" (sic). Assim, o que está expresso no fragmento de análise 
transcrito é um conflito, no interior de Rebeca, de elementos bons e maus que estavam sendo rearranjados, e uma capacidade para a ambivalência que foi sendo progressivamente conquistada. Com efeito, o que parece ter ocorrido com Rebeca é que os seus sintomas melancólicos e obsessivos perderam força - ou função - na medida em que a paciente passou a aceitar e integrar o fato de seu ódio e agressividade em relação aos pais, os quais amava. De acordo com Winnicott (1958/1983), em termos de progresso analítico, a melhor experiência que um analista pode ter é a "observação do crescimento gradativo da capacidade do indivíduo de tolerar os elementos agressivos no seu impulso amoroso primitivo" (p. 26).

Foi estabelecido um tipo de setting no qual o mais importante não foram a interpretações do inconsciente, que só ocorreram (poucas delas) após várias sessões de psicoterapia, mas o manejo, "que é uma forma especializada de cuidar que envolve as intervenções realizadas no setting" (Tosta, 2012, p. 66). Trata-se de um tipo especial de setting onde se privilegia a experiência completa que se dá através da experiência de mutualidade entre o terapeuta e o paciente, bem como do holding (ou sustentação) por parte do profissional. Com efeito, para Tosta (2012), para além do insight e da elaboração do passado, o que é valorizado por Winnicott é o acontecimento na clínica. Assim, foi dada à Rebeca a oportunidade da regressão à dependência em um ambiente previsível, confiável e sensivelmente adaptável às necessidades do paciente, em que "a esperança (da paciente) pode ser ativada e, portanto, a situação de falha precoce pode ser descongelada e experimentada novamente, desta vez em um ambiente adequado" (Tosta, 2017, p. 768, tradução nossa).

É interessante notar que não foram raras as vezes em que Rebeca parecia camuflar (ou se esquivar), através da temática do abuso, muitas das adversidades relacionadas à mãe. Dessa forma, consideramos que, dentro do setting terapêutico, o tema da violência sexual era utilizado tanto para comunicar as vicissitudes que envolviam pai e mãe (a suspeita de que sua progenitora sempre soube do abuso, por exemplo), como também para encobrir como forma de defesa - conteúdos insuportáveis relacionados à sua progenitora. Funcionando como uma espécie de barreira, a temática do abuso sexual infantil precisou ser suficientemente trabalhada e elaborada para que, somente assim, fosse possível a 
emergência à consciência de vivências traumáticas relacionadas à mãe descritas no decorrer deste texto. Próxima de completar dois anos de psicoterapia, diz Rebeca:

o abuso é algo mais manifesto, mais visível, é uma violência mais evidente [...]; mas não foi só isso que me ocorreu, teve toda essa situação com minha mãe, que também são violências, mas que não são tão claras ou fáceis de perceber [...]. As duas coisas [abuso e problemas com a mãe] tiveram muito peso, o que difere é isso (sic).

\section{Considerações finais}

Consideramos que o abuso sexual intrafamiliar ocorrido com Rebeca em sua infância pode ter sido um dos fatores traumáticos que contribuíram para o bloqueio ou interrupção dos processos inerentes ao estágio do concernimento, especificamente a tarefa de diferenciação entre fatos e fantasias e, sincronicamente, a do desenvolvimento da técnica para a aceitação da plena responsabilidade por ideias destrutivas (culpa). A situação de abuso acarretou acentuadas dificuldades em relação à aceitação da responsabilidade pelos impulsos eróticos e destrutivos dirigidos ao pai (agressor), mas também em relação à mãe (conivente). Essa dificuldade aparece na forma de culpa patológica, impossibilitando que envolvimento ou preocupação pudessem ser desenvolvidos por Rebeca. Por isso tudo, acreditamos ser possível relacionar o abuso sexual infantil com a depressão na vida adulta. Tal violência sofrida parece ter sido um fator decisivo para o aparecimento do quadro melancólico, mas não o único. A depressão da paciente parece ter sido resultado de sucessivas falhas ambientais traumáticas ocorridas em sua infância, sendo o abuso sexual o tema predominante e mais recorrente em suas sessões de psicoterapia e, por isso, enfatizado neste estudo. Cabe ser sublinhado que são diversos os tipos de violências associados ao abuso sexual na infância, não podendo este ser analisado de maneira isolada, tanto clínica quanto teoricamente.

Ao longo do processo terapêutico, Rebeca apresentou melhora da sintomatologia depressiva e obsessiva, tais como: abandono dos pensamentos suicidas; diminuição considerável das vezes em que se banhava por dia; mais horas fora da cama e se dedicando a atividades de esporte e lazer, como natação e caminhada; diminuição do sentimento de 
culpa e de inutilidade e; o sentimento de estar começando a viver a própria vida, passando a agir mais por si mesma com base em uma individualidade que não é constituída reativamente, perspectivas essas relacionadas à saúde (Fulgencio, 2016; Winnicott, 1967/2011b). Observamos, ainda, o crescimento gradativo da capacidade da paciente de reconhecer, aceitar e tolerar os elementos agressivos e destrutivos no seu impulso amoroso primitivo. Toda essa melhora foi observada três meses antes da elaboração do presente estudo e se manteve pelo menos até a elaboração do mesmo.

Esses progressos nos fizeram refletir sobre a potência da abordagem psicanalítica e da utilização dos conceitos revisados para a prática clínica e para o estudo das questões em foco. Pensamos que através da transferência com o psicólogo, a paciente pôde reviver momentos angustiantes e internalizar aspectos de uma figura paterna confiável. O manejo realizado no setting e a possibilidade da regressão à dependência no processo analítico foram fundamentais para a melhora de Rebeca, práticas que nos parecem ser úteis para vítimas de traumas infantis e pessoas com depressões impuras. Esse ambiente terapêutico adequado nos possibilitou contribuir para a retomada do desenvolvimento emocional da paciente, sendo fundamental nesse processo a diferenciação entre fatos e fantasias, a integração da destrutividade e da raiva na personalidade, a conquista da capacidade para a ambivalência, a conscientização e elaboração dos sentimentos inconscientes de culpa e o conhecimento da própria sexualidade.

\section{Referências}

Abram, J. (2000). A Linguagem de Winnicott: Dicionário das Palavras e Expressões Utilizadas por Donald W. Winnicott. Rio de Janeiro: Revinter.

Amaral, J. G. P. D. (2006). Os destinos da tristeza na contemporaneidade: uma discussão sobre depressão e melancolia [Dissertação de Mestrado, Pontifícia Universidade Católica do Rio de Janeiro]. Coleção Digital da Pontifícia Universidade Católica do Rio de Janeiro. https:// doi.org/10.17771/PUCRio.acad.8580

Anfusso, A., \& Indart, V. (2009). ¿De qué hablamos cuando hablamos de Winnicott? Montevideo: Psicolibros Waslala. 
Beck, A. T., \& Alford, B. A. (2011). Depressão: Causas e Tratamento. São Paulo: Artmed Editora S.A.

Blas, E., Kurup A. S., \& World Health Organization (WHO). (2010). Equity, social determinants and public health programmes. Geneva: World Health Organization. https://apps.who.int/iris/handle/10665/44289

Cantón-Cortés, D., \& Cortés, M. R. (2015). Consecuencias del abuso sexual infantil: una revisión de las variables intervinientes. Anales de Psicología, 37(2), 607-614. http://doi.org/10.6018/analesps.31.2.180771

Carr, C. P., Martins, C. M., Stingel, A. M., Lemgruber, V. B., \& Juruena, M. F. (2013). The role of early life stress in adult psychiatric disorders: a systematic review according to childhood trauma subtypes. The Journal of Nervous and Mental Disease, 201(12), 10071020. http://doi.org/10.1097/NMD.0000000000000049

Dalgalarrondo, P. (2008). Psicopatologia e semiologia dos transtornos mentais. Porto Alegre: Artmed.

De Bellis, M. D., \& Zisk, A. (2014). The Biological Effects of Childhood Trauma. Child and Adolescent Psychiatric Clinics of North America, 23(2), 185-222. http://doi.org/10.1016/j.chc.2014.01.002

Feitosa, F. B. (2014). A depressão pela perspectiva biopsicossocial e a função protetora das habilidades Sociais. Psicologia: Ciência e Profissão, 34(2), $\quad 488-$ 499. https:// doi.org/10.1590/1982-3703000992013

Ferenczi, S. (1992). Confusão de língua entre os adultos e a criança: a linguagem da ternura e da paixão (A. Cabral, Trad.). In S. Ferenczi, Obras Completas: Psicanalise IV (pp. 97106). São Paulo: Martins Fontes. (Obra original publicada em 1933[1932])

Figueiredo, Â. L. (2012). Associação entre trauma na infância e transtorno do humor na vida adulta [Tese de Doutorado, Pontifícia Universidade Católica do Rio Grande do Sul]. Repositório Institucional PUCRS. https://hdl.handle.net/10923/4787

Figueiredo, Â. L., Dell'aglio, J. C., Silva, T. L., Souza, L. D. M., \& Argimon, I. I. L. (2013). Trauma infantil e sua associação com transtornos do humor na vida adulta: uma revisão sistemática. Psicologia em Revista, 19(3), 480-496. http://doi.org/DOI$10.5752 / P .1678-9563.2013 v 19 n 3 p 480$ 
Florentino, B. R. B. (2015). As possíveis consequências do abuso sexual praticado contra crianças e adolescentes. Fractal: Revista de Psicologia, 27(2), 139-144. https:// doi.org/10.1590/1984-0292/805

Freud, S. (1972). Três ensaios sobre a teoria da sexualidade (J. Salomão, Trad.). In S. Freud, Obras completas (v. 7, pp. 123-252). Rio de Janeiro: Imago Editora LTDA. (Obra original publicada em 1905)

Fulgencio, L. (2004). A noção de trauma em Freud e Winnicott. Natureza humana, 6(2), 255270. http://pepsic.bvsalud.org/pdf/nh/v6n2/v6n2a03.pdf

Fulgencio, L. (2016). Por que Winnicott? São Paulo: Zagodoni.

Goldgrub, F. (1988). Trauma, amor e fantasia: história lógica da teorização do inconsciente na obra de Freud. São Paulo: Editora Escuta.

Habigzang, L. F., Koller, S. H., Azevedo, G. A., \& Machado, P. X. (2005). Abuso sexual infantil e dinâmica familiar: aspectos observados em processos jurídicos. Psicologia: Teoria e Pesquisa, 21(3), 341-348. https://doi.org/10.1590/S0102-37722005000300011

Khan, M. M. R. (1984). O conceito de trauma cumulativo (G. Vaz, Trad.). In M. M. R. Khan, Psicanálise: teoria, técnica e casos clínicos (pp. 57-75). Rio de Janeiro: Francisco Alves. (Obra original publicada em 1963)

Konradt, C. E., Jansen, K., Magalhães, P. V. S., Pinheiro, R. T., Kapczinski, F. P., Silva, R. A. et al. (2013). Trauma precoce e transtornos de humor em jovens. Archives of Clinical Psychiatry, 4O(3), 93-96. https://doi.org/10.1590/S0101-60832013000300003

Louzã Neto, M. R., \& Elkis, H. (2007). Psiquiatria Básica. Porto Alegre: Artmed.

Martins, C. M. S. (2012). Análise da ocorrência de estresse precoce em pacientes psiquiátricos adultos [Dissertação de Mestrado, Universidade de São Paulo]. Biblioteca Digital de Teses e Dissertações da USP. http://doi.org/10.11606/D.17.2012.tde$30052012-130123$

Moraes, A. A. R. E. (2014). Depressão na obra de Winnicott. São Paulo: DWW Editorial.

Naffah Neto, A., \& Cintra, E. M. U. (2019). Paradoxo, noite e mistério: os labirintos da pesquisa psicanalítica. In I. Kublikowski, E. M. S. P. Kahhale, \& R. M. Tosta (Orgs.), Pesquisas em psicologia clínica: contexto e desafios (pp. 13-34). São Paulo: EDUC. 
Negele, A., Kaufhold, J., Kallenbach, L., \& Leuzinger-Bohleber, M. (2015). Childhood Trauma and Its Relation to Chronic Depression in Adulthood. Depression Research and Treatment, 2015, 1-11. https://doi.org/10.1155/2015/650804

Numhauser, J., \& Soto, P. (2006). Consejos en la psicoterapia de mujeres víctimas de incesto: Revisión de 59 casos. Revista chilena de neuro-psiquiatría, 44(4), 271 281. https://doi.org/10.4067/S0717-92272006000400006

Oliveira, J. R., Costa, M. C. O., Amaral, M. T. R., Santos, C. A., Assis, S. G., \& Nascimento, O. C. (2014). Violência sexual e coocorrências em crianças e adolescentes: estudo das incidências ao logo de uma década. Ciência \& Saúde Coletiva, 19(3), 759-771. https:// doi.org/10.1590/1413-81232014193.18332013

Perón, P. R. (2007). Considerações teóricas ferenczianas sobre o trauma. Psicologia Revista, 16(1/2), 13-27. https://revistas.pucsp.br/index.php/psicorevista/article/view/18053.

Sant'Anna, P. A., \& Baima, A. P. S. (2008). Indicadores clínicos em psicoterapia com mulheres vítimas de abuso sexual. Psicologia: ciência e profissão, 28(4), 728-741. https:// doi.org/10.1590/S1414-98932008000400006

Serafim, A. D. P., Saffi, F., Achá, M. F. F., \& Barros, D. M. D. (2011). Dados demográficos, psicológicos e comportamentais de crianças e adolescentes vítimas de abuso sexual. Archives of Clinical Psychiatry (São Paulo), 38(4), 143-147. https:// doi.org/10.1590/S0101-60832011000400006

Silva, D. Q. (2013). A pesquisa em psicanálise: o método de construção do caso psicanalítico. Estudos de Psicanálise, (39), 37-45. http://pepsic.bvsalud.org/pdf/ep/n39/n39a04.pdf

Silva, C. M., \& Macedo, M. M. K. (2016). O método psicanalítico de pesquisa e a potencialidade dos fatos clínicos. Psicologia: Ciência e Profissão, 36(3), 520-524. https:// doi.org/10.1590/1982-3703001012014 
Steck, A., \& Steck, B. (2016). Brain and Mind: Subjective Experience and Scientific Objectivity. New York: Springer.

Tosta, R. M. (2012). Os princípios das consultas terapêuticas como parâmetros para a clínica winnicottiana. In J. Outeiral, M. Zart, J. Amaral, \& H. Pinheiro (Orgs.), Winnicott: Seminários Cearenses (pp. 63-70). São Paulo: Zagodoni.

Tosta, R. M. (2017). Consultas terapêuticas: fenómenos curativos y salud. Revista Latinoamericana de Psicopatologia Fundamental, 20(4), 762-775. https:// doi.org/10.1590/1415-4714.2017v20n4p762.9

Tosta, R. M. (2019). O fazer do pesquisador e a pesquisa psicanalítica. In I. Kublikowski, E. M. S. P. Kahhale, \& R. M. Tosta (Orgs.), Pesquisas em psicologia clínica: contexto e desafios (pp. 285-304). São Paulo: EDUC.

Vidal, M., \& Lowenkron, T. (2008). Sobre a depressão pura. Revista Brasileira de Psicanálise, 42(1), 52-59. http://pepsic.bvsalud.org/pdf/rbp/v42n1/v42n1a06.pdf

Winnicott, D. W. (1983). Psicanálise do sentimento de culpa. In D. W. Winnicott, $O$ ambiente e os processos de maturação: estudos sobre a teoria do desenvolvimento emocional (pp. 19-30). Porto Alegre: Artmed. (Obra original publicada em 1958)

Winnicott, D. W. (1983). O desenvolvimento da capacidade de se preocupar. In D. W. Winnicott, $O$ ambiente e os processos de maturação: estudos sobre a teoria do desenvolvimento emocional (pp. 70-78). Porto Alegre: Artmed. (Obra original publicada em 1963)

Winnicott, D. W. (1990). Natureza Humana. Rio de Janeiro: Imago.

Winnicott, D. W. (1993). A posição depressiva no desenvolvimento emocional normal. In D. W. Winnicott, Textos selecionados: da pediatria à psicanálise (pp. 437-458). Rio de Janeiro: Francisco Alves. (Obra original publicada em 1954)

Winnicott, D. W. (1994). O conceito de trauma em relação ao desenvolvimento do indivíduo dentro da família. In C. W. Winnicott, R. Sherpherd, \& M. Davis (Orgs.), Explorações psicanalíticas: D. W. Winnicott (pp. 102-115). Porto Alegre: Artes Médicas. (Obra original publicada em 1965) 
Winnicott, D. W. (2011a). A família afetada pela patologia depressiva de um ou ambos os pais. In D. W. Winnicott, A Família e o desenvolvimento individual (pp. 73-88). São Paulo: Martins Fontes. (Obra original publicada em 1958[1965])

Winnicott, D. W. (2011b). O valor da depressão. In D. W. Winnicott, Tudo começa em casa (pp. 59-68). São Paulo: Editora WMF Martins Fontes. (Obra original publicada em 1963) Winnicott, D. W. (2011 b). O conceito de indivíduo saudável. In D. W. Winnicott, Tudo começa em casa (pp. 3-22). São Paulo: Editora WMF Martins Fontes. (Obra original publicada em 1967)

Winnicott, D.W. (2012). O desenvolvimento da capacidade de envolvimento. In D. W. Winnicott, Privação e delinquência (pp. 111-117). São Paulo: Editora WMF Martins Fontes. (Obra original publicada em 1963[1962])

World Health Organization (WHO). (2003). Guidelines for medico-legal care for victims of sexual violence. Geneva: WHO. https://www.who.int/violence_injury_prevention/publications/violence/med_leg_guideli nes/en/

World Health Organization (WHO). (2017). Depression and Other Common Mental Disorders: Global Health Estimates. Geneva: WHO. https://apps.who.int/iris/handle/10665/254610

Yin, R. K. (2015). Estudo de caso: planejamento e métodos (5a ed.). Porto Alegre: Bookman.

\footnotetext{
i Entendemos que a definição ferencziana de trauma se assemelha mais àquela de Freud, que introduziu conceitos metapsicológicos para pensar a noção de trauma e o considera como um afluxo excessivo de excitação, do que àquela defendida por Winnicott, que não utiliza a "noção de pulsão, de libido, nem mesmo da de um aparelho psíquico com suas instâncias" (Fulgêncio, 2004, p. 267). A psicanálise freudiana concebe "todo trauma como uma excitação de natureza sexual, cujo cenário maior é dado pelo complexo de Édipo, não adequadamente descarregada pelo indivíduo" (Fulgencio, 2004, p. 262). Para Freud (1920/1976) "um acontecimento como um trauma externo está destinado a provocar um distúrbio em grande escala no funcionamento da energia do organismo [...]” (p. 45). Por outro lado, para Winnicott (citado por Fulgencio, 2004), o trauma é explicado em termos das relações humanas e do amadurecimento emocional, sem a necessidade de uma metapsicologia.

iiWinnicott (1965/1994), também fala de uma inocência infantil da menina em uma fase pré-púbere ou pré-sexual. Em suas palavras, "ela (menina/paciente) não pôde colocar em palavras a natureza completa do trauma, o fato de
} 
que a doce inocência que pertence à fase de seu desenvolvimento emocional [...] estava sendo estragada pela introdução prematura da sexualidade de um homem [...]" (Winnicott, 1965/1994, p. 103, grifos nossos). 